EASTERN REVIEW 2019, T. 8

\author{
Victor Laputsky \\ (iD https://orcid.org/0000-0002-2514-9608 \\ Belarusian State University, Minsk, Belarus \\ Department of Social Communication \\ e-mail: valnoros@gmail.com
}

\title{
The adaptation of students during academic mobility processes: The case of Belarus
}

\begin{abstract}
The article describes the experience of Belarus in the field of international academic mobility. The purpose of the article is to reveal the theoretical and methodological aspects of the internationalization of higher education and academic mobility and describe the current situation on the integration of Belarus into the international context, from a sociological and statistical perspective. In view of the significant number of Belarusian students in Polish and Eastern European universities, the topic is relevant in the context of the study of academic mobility in Eastern Europe. As part of the first task, the theoretical aspects of studying the internationalization of higher education in the country are described - with justification for the development of both the external and internal internationalization, as well as a description of various types of students' adaptation when studying abroad (academic, linguistic, socio-cultural). As part of the second task, the results of the author's sociological study are presented, which includes two main components. Firstly, the results of a survey devoted to the study of the views of Belarusian students regarding academic mobility (including cognitive, affective and behavioural aspects) are presented. Secondly, the results of a series of in-depth interviews among participants in the processes of academic mobility aimed at studying the practices of Belarusian students staying abroad for educational purposes are considered. The studies showed the need to increase the awareness of Belarusian students about the possibilities of academic mobility (the vast majority of students have incomplete or fragmented ideas about the possibilities of academic mobility), as well as the problem of the incomplete involvement of the Belarusian higher education system in the international context (the activity of students participating in exchange programs is not counted at Belarusian
\end{abstract}


universities). In accordance with the results, recommendations are given for the further integration of the Belarusian higher education system into the international context.

Keywords: international cooperation in education, Belarus, academic mobility, academic adaptation.

\section{Introduction}

Over the past ten years, the process of integrating Belarus's educational system into the international context has become a hot topic in Belarusian institutions of higher education. Furthermore, the inclusion of Belarus in the Bologna process is an additional challenge for the education sector (Titarenko, Zaslavskaja, 2019: 102). At the same time, the involvement of universities in the European educational space can become one of the main ways to activate the work of educational institutions and stimulate positive changes in the education system of the Republic of Belarus.

The annual data on Belarusians going abroad for educational purposes differ depending on the source of the data. For example, according to one monitoring study, the Eurostudent V international project, no more than $1 \%$ of Belarusian students participate in academic mobility (The concept of the development..., 2016). According to other data, annually more than 3.5 thousand students and more than 3.7 thousand pedagogical workers of Belarus go abroad as part of academic mobility (Education in the Republic of Belarus, 2019). The small percentage of Belarusian students studying abroad indicates that the level of involvement of the educational system of Belarus in the processes of academic mobility is low.

Belarusian students participate in academic mobility during international educational programs (ERASMUS+, IAESTE, LINGUA, etc.) and interstate and inter-university agreements. It is noteworthy that, firstly, these programs have a small focus, and, secondly, Belarus is more a consumer of academic mobility services than an exporter. For example, in 2015 there were 153 Belarusian students who completed placements in foreign universities participating in the Erasmus + program, while only 22 foreign students visited the Belarusian universities themselves, under the program. Poland is one of the leading Erasmus + participants, with more than 4 thousand students and staff annually (Erasmus..., 2013). The insignificant share of the exchange programs participants indicates that Belarus is still at the initial stage of integration into the international education system (The concept of the development..., 2016).

At the same time, despite the small number of Belarusian students studying abroad, there is a certain positive trend. In comparison to 2011, the number of Belarusian students who participated in international academic exchange programs increased by $86 \%$ (Education in the Republic of Belarus, 2019). The 
greatest number of Belarusian students were recorded in Russia, Lithuania, and Poland. In Russia, for 2018/2019, 7.3 thousand Belarusian students were enrolled at various levels of education (Russian statistical yearbook, 2018). The large number of Belarusians in Russian universities is due to the low number of barriers for studying abroad, similar higher education systems, and no need for linguistic and sociocultural adaptation.

Polish universities are second in popularity among Belarusians. According to the Ministry of Science and Higher Education of Poland, in the academic year 2018/2019, 7,314 Belarusian citizens studied in Poland. Only Ukraine has more students in Poland: Ukrainians make up about 50\% (39,203 people) of the total number of foreign students in Poland. Given the number of residents of both countries (Belarus: 9.5 million, Ukraine: 47 million), the share of Belarusian students in Poland is almost two times higher than in the case of Ukrainian youth (Higher education institutions..., 2018). Universities in Poland are usually chosen by those Belarusians who have Polish roots. Such students can count on free admission and even a scholarship from the Polish universities. "The Study in Poland" program annually organises an Education and Career educational exhibition, which takes place in the capital of Belarus. The small number of barriers results in a constant flow of Belarusian students studying at Polish universities.

\section{The internationalization of higher education: theoretical aspects}

The theoretical frame of studying educational internationalization in this article is based on the theories of globalization by R. Robertson and P. Sztompka. R. Robertson (one of the main theorists of globalization and a lecturer at the University of Aberdeen) considers globalization in the cultural sphere as "glocalization" (this term is also used by other theorists of globalization - Z. Bauman, B. Wellman, etc.), i.e. the process of preserving and developing the local characteristics of any territory against the background of the influence of globalization processes. Such optics are relevant in the case of considering the integration of countries into international educational cooperation - despite being involved, they retain local features (Robertson, 1992). According to P. Sztompka (professor of sociology at the Jagiellonian University and the author of the theory of social trust), the involvement of the national higher education system in the global context can be considered as a traumatic situation leading to ambiguous consequences. The transformation of a country's higher education system under international influence can lead both to positive changes and to the deformation of the existing system. It creates the risk of incomplete involvement in a global context - which could potentially lead to a state of 
trauma in the system (Sztompka, 2000: 450). The impossibility of achieving a unified social space in the field of education makes relevant the studying of both the internationalization of the country's higher education system and the adaptation of participants in academic exchanges.

According to P. Altbach (the founding director of the Boston College Center for International Higher Education), the internationalization of higher education involves the verification of knowledge acquired by students at universities outside the country; increases their mobility; and contributes to the exchange of knowledge between countries or universities, which positively affects the socio-economic development of the countries. Educational integration allows a country hosting foreign students to receive additional funds, through international programs and payment for educational services by foreign students. As a result, integrative processes can be useful both for individual young people studying abroad, and for the universities and the state (Altbach, 2001: 6).

In OECD studies, the internationalization of higher education is seen as "a process through which interactions at the level of government, higher education institutions, social groups and individuals receive an international dimension" (Knight, 2015: 1). The result of this process is the formation of a new educational environment, which is a synthesis of the best achievements of the foreign education system and the specifics of the social structure, economy, politics, and traditions of the state.

Conceptually, the implementation of this process provides for the updating of two aspects: internal and external (Stukalova et al., 2015: 276). Internal internationalization implies the creation of a culture and climate directly within the educational institution, within which there is an intercultural and interethnic understanding. This process includes the implementation of all academic programs, projects, and studies, which contain an international dimension through their compliance with international standards, the attracting of foreign developments, or through joint implementation with foreign partners. External internationalization covers the process of exporting educational services to foreign countries through various educational technologies and through agreements between countries and between universities (Stukalova et al., 2015: 276).

In the context of internationalization, participants in the processes of academic mobility themselves play an important role. P. Osipov (the professor of Kazan National Research Technological University) shares the idea of considering participants in various educational programs or processes of academic mobility as acting subjects. Analysing the internationalization of education in Russia, the author emphasizes that the current state of Russian universities from the point of view of international activity does not meet the goals. Osipov notes that "there are no significant barriers to the international activities of teachers and students in Russian realities. The question of the state of international activity of Russian 
universities is reduced to the question of abilities (professional competencies) and the motivation of potential participants". This statement leads to the conclusion about "the important status of participants in academic mobility as active actors in the internationalization of education" (Osipov, Ziatdinova, 2017: 66).

In educational integration, both participants of academic mobility processes (students, staff) and the organizations that regulate their activities (universities, states) act as agents that contribute to the success of the process. Participants in the processes of academic mobility in the future contribute to its further intensification (both through the implementation of the experience gained abroad and its transfer of experience to potential participants in this process) (Wende, 2015: 85; Campbell, 2015: 287).

In the context of educational integration, the issue of the adaptation of participants in this process is relevant. It is not enough to attract foreign students or specialists to the country. It is necessary to create a comfortable environment, both from an educational point of view (the adaptation of the curriculum, the educational process) and from the social one (ensuring living conditions in the country). The process of integrating education can't be effective without social technologies aimed at providing favourable conditions both for international and local students, participating in the academic mobility processes (Laputsky, 2019: 99).

In the case of educational integration, representatives in the field of educational sociology distinguish three areas of adaptation: academic, linguistic, and sociocultural. The adaptation of foreign students to the new environment consists of certain stages: entering the student environment; mastering the basic norms of a multi-ethnic group; developing one's own style of behaviour; forming a stable positive attitude towards the future profession; overcoming the "language barrier"; and reinforcing a sense of academic equality. The above components are in close interconnection, and each foreign student, when entering a university whose studies are in a foreign language, is faced with the task of simultaneously adapting in three areas at once (Sakhieva et al., 2015: 257).

Academic adaptation relates to the pace of adaptation of an educational migrant to the conditions of study at a foreign higher education institution and country. It includes adapting to the new pedagogical system; following the formal requirements of the educational process; as well as mastering the types and organizational forms of educational activity. An educational migrant, in the framework of academic adaptation, is faced with the need to simultaneously adapt to the faculty, administration, dormitory standards, and study group, which imposes certain restrictions on him at the beginning of his studies at the university. (Cheng, Fox, 2008: 308).

Linguistic adaptation takes place when training in a foreign institution is not conducted in the native language of the educational migrant. In order to reduce the barrier, educational institutions practice preliminary language training at 
preparatory faculties (intended for foreign students), which lasts about a year. Within this period, a foreign student is given basic knowledge of the language, which in the future will allow them to absorb the material of subsequent courses. However, it should be noted that the language adaptation of a foreign student does not end when he graduates from the preparatory faculty. It continues until the completion of studies at the university. For example, language adaptation takes place while an educational migrant communicates with the local students (within the training group or outside of it) and its pace, respectively, depends on the intensity of such processes (Ren et al., 2007: 12; Sánchez Hernández, 2013: 188).

In the case of communication, adaptation in the sociocultural space is relevant. Sociocultural adaptation is a complex multifaceted process of interaction between the individual and the new socio-cultural environment, during which foreign students, having specific ethnic and psychological characteristics, are forced to overcome various kinds of psychological, social, moral, and religious barriers, in order to master new types of activities and behaviours. Sociocultural adaptation is the most complex process of all three presented since it affects both the person's communication with the local students and their interaction with other foreign students who arrived from other countries. The pace of sociocultural adaptation depends both on personal qualities (its tolerance towards representatives of other cultures, faiths, nationalities), and on its host (university, study group, etc.) (Georgette, 2011: 25).

The sociocultural adaptation of foreign students in the local group is a twoway process because it is carried out not only by foreigners themselves but also by the host country. And yet this is not a guarantee of the successful sociocultural adaptation of an individual. Depending on the cultural distance of the already existing collective and the migrant trying to get into it, it is possible to form a cultural pluralism in the group, as well as to organize a "friend or foe" system with the isolation of the migrant from the group. The barriers to the entry of a foreign student into the group by the receiving side are student rejection due to insufficient language skills, too great a cultural distance, or a low level of cultural pluralism (Georgette, 2011: 25).

The adaptation of a foreign student in a new country and university is a complex process, depending on the soft skills of the person and the level of internal internationalization of the university. During the learning process, it comes down to overcoming a number of barriers of an academic and socio-cultural nature, and, if successful, leads to the acquisition of new experience and the expansion of current professional competencies. 


\section{The Belarusian practice of academic mobility}

In order to study the current involvement of Belarusian student youth in international integrative processes, a study was conducted from 2017 to 2019 aiming to examine the cognitive and affective attitudes of Belarusian students and graduates who studied abroad. The object of the study includes Belarusian students and graduates who became participants in the processes of academic mobility. The purpose of the study was to review the practices of Belarusian students and graduates participating in educational programs and internships abroad in the context of academic mobility. The following tasks were set:

1) to study the cognitive aspect of the attitude of Belarusian students and graduates regarding the possibility of studying abroad;

2) to consider the motivational attitudes of Belarusian students and graduates when studying abroad;

3) to identify the main barriers to participation in forms of academic mobility;

4) to study the attitude of Belarusian students and graduates who have become participants in the processes of academic mobility in relation to this phenomenon;

5) to study Belarusian students and graduates assessment of their experience of studying abroad in terms of acquired professional competencies and life experience.

Empirical material was collected through in-depth interviews of participants of academic exchanges and through questionnaires given to all students who did not participate in academic exchange programs or other forms of academic mobility. The choice of in-depth interviews as the main research method is due to the capabilities of this method to solve the tasks. One of the main advantages of in-depth interviews is the semi-formalization of the conversation scenario and the possibility of changing it during the conversation depending on the research tasks. In-depth interviews also allow personal information to be obtained and reveal the subjective attitude to the issue under study; as well as to obtain high-quality information on a wide range of issues. The motives for participation in academic mobility programs, the pace of adaptation to life abroad, the attitude to higher education, are personal topics for each participant and as such the respondent will not always be ready to present them to the public. Therefore, it's preferable to collect such data through in-depth interviews.

In total 40 interviews were conducted with people who studied in Poland, the Czech Republic, Russia, China, Lithuania, Latvia, Portugal, Spain, Germany, and Sweden. The average interview duration was one hour.

In the survey, the focus was on students who did not participate in academic exchange programs. It is important that in the toolkit itself, the main emphasis was placed on open-ended questions - respondents were asked to write in their own words an opinion on the proposed question instead of choosing pre-defined 
answer options. On the one hand, such a solution slightly increases the share of cases, when respondents ignore the open-ended questions, and the time needed to process the received questionnaire array significantly increases; however, on the other hand, it avoids potential data distortion in situations where the respondent has the opportunity to choose any answer option, even without a stable position or information on the question.

The sample set of the questionnaire was 420 respondents studying in 7 universities of Belarus. The selected universities are located in Minsk and are the largest ones in the country among the three main directions of higher education - natural sciences, technology, and social sciences. Students for the survey at each university were selected by random sampling.

The study did not include those students who went to study abroad after graduation from school. The focus on academic exchanges participants is related to the possibility to evaluate the activities of Belarusian universities in integrating Belarusian higher education into the international context. In the case of going to study directly at a foreign university after leaving school, personal opportunities are the main driver. In the case of academic exchanges, universities are an important factor. This leads to the study of this particular aspect of academic mobility.

The study showed the need for the formation of international competency among the students. This is expressed both in the development of a level of awareness about the international activities of the university by students and in creating the motivation among students to participate in such activities. The questionnaire highlighted how about $60 \%$ of the students surveyed (who did not participate in any exchange programs) could not name a single academic exchange program. The most popular program was Erasmus + , it was mentioned by $63 \%$ of those who mentioned any educational programs. Among other programs, students also mentioned Hanban, DAAD and Au Pair. It is noteworthy, that among the international student exchange programs, the Work \& Travel program (not specializing in education, but a peculiar form of tourism) was chosen as a program by about $30 \%$ of those who mentioned any programs. This fact speaks not only about the low level of awareness of those surveyed but also about the distorted ideas of students concerning what an international exchange of students is. For students who participated in academic exchange programs or other forms of academic mobility, the main source of information was the information they found on the Internet and personal acquaintances. 


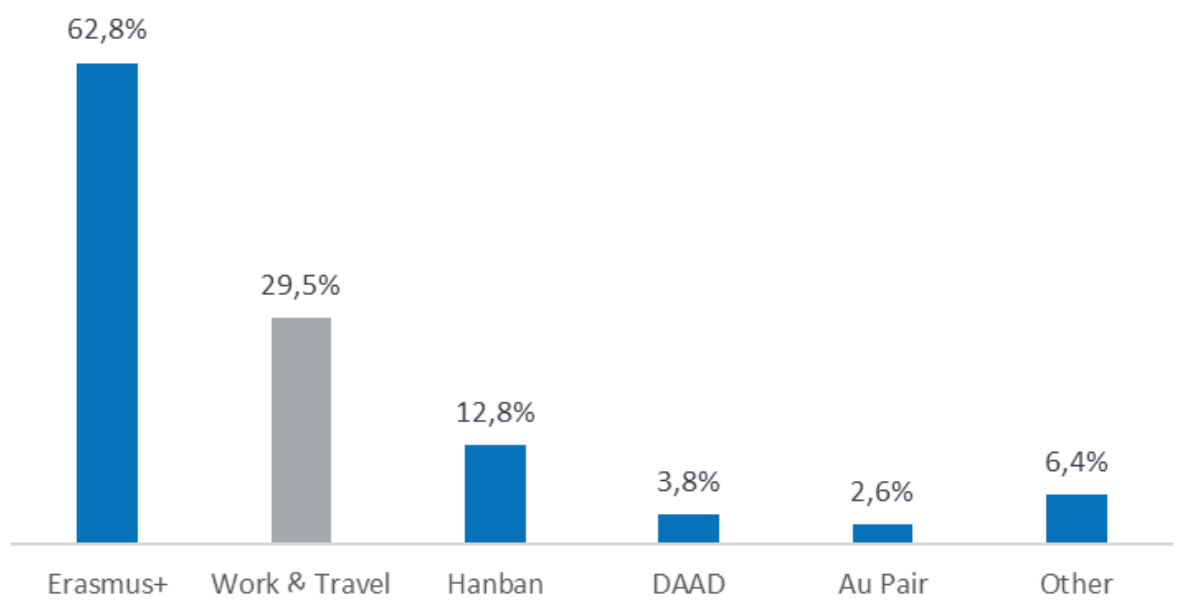

Figure 1. Distribution of answers to the question: What international academic exchange programs can you name, $\mathrm{n}=168$

Source: based on author's calculations.

It is possible to solve this problem through the implementation of information activities aimed at increasing awareness of the various forms of academic mobility, as well as introducing courses in the curriculum aimed at developing mobile competence. This will allow both the increase of the participation of students in this segment and the reduction of the number of socio-cultural barriers encountered when deciding on a trip abroad for educational purposes.

That said, even with a low level of awareness, the attitude towards mobility is predominantly positive. Almost $90 \%$ of all respondents rated this phenomenon positively and expressed a desire to participate in it. The desire to gain new experience, make new acquaintances and raise the level of language proficiency have been distinguished as the main motives. It is noteworthy that students did not indicate professional motives - the share of answers related to the development of professional competencies or acquaintance with another educational system was minimal.

The positive impact of participation in academic exchanges was noted by the participants in academic exchanges during the in-depth interviews. The interviewees noted the impact of participation in academic exchange programs on their personal development (broadening their horizons, gaining experience in a completely different socio-cultural environment) and, to a lesser extent, the impact on their professional development. In rare cases, it was noted that participation in exchange programs did not affect its participants in a professional way, however, it was still useful in terms of gaining new experience that was impossible in Belarus.

From the other side, the study showed the need to address the level of inclusion of various international educational programs in Belarusian higher education. 
During the survey and in-depth interviews, Belarusian students identified three major barriers to participation in academic exchanges. The first is the financial factor: since most universities are not ready to take over the costs of study programs, students are forced to rely on personal financial opportunities. The second significant factor relates to personal fears: respondents are not always psychologically ready to be in a foreign country with a completely different way of life for a long period of time. This factor includes the problem of adaptation - both in academic and socio-cultural ways. Students who participated in international academic programs mentioned that this problem was the most significant during the first months - but later the overcoming of this becomes the main driver of personal development.

There exist situations where expectations do not match the result of training. These situations occur if there is incomplete information about the study-abroad program, the student's personal circle of contacts has no experience of such trips or there exists incorrect expectations regarding the impact on subsequent scientific or professional activities. These reasons create an additional need for informing students about the contents of various foreign programs, organizing events that facilitate the receipt of this kind of information and facilitate more successful adaptation.

Table 1. The main barriers of academic mobility for Belarusian students (Distribution of answers on the question: What is the main barrier to participation in international exchange programs for you, $n=420$ )

\begin{tabular}{|c|c|c|}
\hline Barrier & Description & Share, \% \\
\hline Financial barrier & Inability to pay for education and residence abroad & 25.78 \\
\hline Personal affairs & $\begin{array}{c}\text { Students' fears of inability to socioculturally and } \\
\text { academically adapt }\end{array}$ & 15.63 \\
\hline $\begin{array}{l}\text { Combining of } \\
\text { studying }\end{array}$ & $\begin{array}{l}\text { The difficulty of combining studies abroad during the } \\
\text { academic program and at the native university }\end{array}$ & 12.50 \\
\hline Language barrier & Lack of a proficiency level in a foreign language & 9.38 \\
\hline $\begin{array}{l}\text { Documents } \\
\text { preparation }\end{array}$ & $\begin{array}{l}\text { Difficulties in preparing a package of documents for } \\
\text { studying abroad }\end{array}$ & 8.59 \\
\hline Lack of information & $\begin{array}{l}\text { Lack of information on possible academic mobility } \\
\text { programs }\end{array}$ & 7.81 \\
\hline Other & Other barriers & 10.16 \\
\hline
\end{tabular}

Source: based on author's calculations.

The third significant factor, raised by students during the survey, is the difficulty of combining study abroad under the academic exchange program and study at a Belarusian university. Even though universities participate in such programs as ERASMUS+, DAAD, etc., the question of their inclusion is still open. Students participating in these programs are forced to solve issues of combining 
them with continuing education at their university. Staying abroad for educational purposes, with rare exceptions, is considered by Belarusian universities simply as a pass for part of the educational program, without the possibility of considering activity during participation in the exchange programs. For students, this becomes one of the most significant deterrents when deciding on participation in educational programs.

Unfortunately, normative documents in Belarus do not provide conditions under which students can continue to study abroad without hindrance while maintaining their former status at a Belarusian university. Due to this, the combining of studying at home university and abroad is a personal responsibility of the students themselves. Since, according to students answers during in-depth interviews and questionnaires, the administration of universities does not always facilitate the participation of students in academic exchange programs, this is also a significant barrier.

It is possible to solve this contradiction by implementing a student activity accounting system at home universities for students studying abroad. To some extent, the credit system adopted by the Bologna universities is designed to solve this problem. However, today its existence in Belarusian universities is difficult to consider manifest - the implementation of a credit system in Belarusian universities is at its initial stage. Solving the issue of including students' activity abroad in educational programs could reduce the number of barriers and make participation in international educational programs more attractive for students.

So, there is a need to intensify the activities of universities in carrying out activities aimed at developing international competence among students. This is expressed both in the development of the level of awareness about the international activities of the university by students and in creating motivation among students to participate in such activities. The solution to this issue is possible through the implementation of information events aimed at increasing the awareness of the various forms of academic mobility, introducing courses in the curriculum aimed at developing mobile competence; as well as (in the case of foreign students) the formation of international competence. Such changes will reduce the number of barriers for visiting students and the local population, thereby positively influencing the educational process.

\section{Conclusion}

The integration of the Belarusian higher education system into the international context is a complex process that affects both academic and socio-cultural aspects and requires the development and implementation of social 
technologies. The analysis of the aforementioned studies allows us to make the following conclusions:

1. Belarus is still at the initial stage of integrating higher education into the international context. Even if there is a considerable number of agreements with various universities and participation in many international exchange programs, internal internationalization (first of all, regarding the regulatory aspect) needs to be improved.

2. The level of awareness of Belarusian youth about academic exchange programs is at an average level - there were many respondents who, although did not participate in academic mobility programs, knew about such programs as Erasmus+, DAAD, Qu Pair, and others. However, the share of those who do not know about any academic exchange programs is quite high. Therefore, there is a need to improve the mechanisms of informing Belarusian youth about academic exchange programs.

3. There is a positive attitude of Belarusian youth to the academic mobility processes. Both participants of academic mobility programs and non-participants positively evaluated this process - however, not from the point of view of professional skills, but from the point of view of personal development.

4. On the other hand, there is a mixed assessment of the implementation of the integration of Belarusian higher education into the international context from the point of Belarusian students participated in this process. Students experience certain difficulties in mastering the curriculum and combining it with studying at their home university; as well as in adaptation whilst participating in programs.

\section{References}

Altbach, Ph. 2001. Internationalization and Exchanges in a Globalized University. Journal of Studies in International Education 5(1), pp. 5-25.

Campbell, T. 2015. A phenomenological study on international doctoral students' acculturation experiences at a U.S. university. Journal of International Students 5, pp. 285-299.

Cheng, L. Fox, J. 2008. Towards a better understanding of academic acculturation: Second language students in Canadian Universities. Canadian Modern Language Review 65, pp. 307-333.

The concept of the development of international academic mobility within the European Higher Education Area. Version 2, 19.09.2016. 2016. https://conference.bsu.by/mod/ resource/view.php?id=332 (accessed 2.12.2019). 
Education in the Republic of Belarus. 2019, http://www.belstat.gov.by/ofitsialnaya-statistika/ solialnaya-sfera/obrazovanie/publikatsii_8/index_13887/(accessed 2.12.2019).

Erasmus: Facts. Figures and Trends. 2013, https://ec.europa.eu/assets/eac/education/ library/statistics/erasmus-plus-facts-figures_en.pdf (accessed 2.12.2019).

Georgette, P.W. 2011. Fitting-In: Sociocultural Adaptation of International Graduate Students, presented at the 42nd annual meeting of the Northeastern Educational Research Association, October 19-21. 2011.

Higher education institutions and their finances in 2018, https://stat.gov.pl/en/topics/ education/education/higher-education-institutions-and-their-finances-in-2018,2,12. html (accessed 2.12.2019).

Knight, J. 2012. Student Mobility and Internationalization: trends and tribulations. Research in Comparative and International Education 7(1), pp. 20-33.

Knight, J. 2015. Updated definition of internationalization. International Higher Education 33 , pp. 2-3.

Laputsky, V. 2019. Problem of adaptation of foreign students in belarusian higher education. SOTIS - Social Technologies. Research 2, pp. 99-106.

Osipov, P., Ziatdinova, Y. 2017. Teachers and students as subjects of internationalization of education. Sociological Studies 3, pp. 64-69.

Ren, J., Bryan, K., Min, Y., Wei, Y. 2007. Language preparation and the first year experience: What administrators and policy makers should know. Florida Journal of Educational Administration \& Policy 1, pp. 11-24.

Robertson, R. 1992. Globalization: Social theory and Global Culture. London: Sage.

Russian statistical yearbook 2018, https://www.gks.ru/free_doc/doc_2018/year/year18. pdf (accessed 2.12.2019).

Sakhieva, R., Semenova, L., Muskhanova, I., Yakhyaeva, A., Iskhakova, R., Makarova, E., Shafigullina, L. 2015. Academic Mobility of High School Students: Concept, Principles, Structural Components and Stages of Implementation. Journal of Sustainable Development 8, pp. 256-262.

Sánchez Hernández, P. 2013. Lexical Bundles in Three Oral Corpora of University Students. Nordic Journal of English Studies 13, pp. 187-209.

Spack, R. 1997. The acquisition of academic literacy in a second language: A longitudinal case study. Written Communication 14, pp. 3-62.

Stukalova, I., Shishkin, A., Stukalova, A. 2015. Internationalization of Higher Education: A Case of Russian Universities. Economics and Sociology 8(1), pp. 275-286.

Sztompka, P. 2000. Cultural Trauma: The Other Face of Social Change. European Journal of Social Theory 3, pp. 449-466.

Titarenko, L., Zaslavskaya, M. 2019. European integration of the systems of higher education of Belarus and Armenia. Journal of the Belarusian State University. Sociology 1, pp. 102-112.

Wende, M. 2015. International Academic Mobility: Towards a Concentration of the Minds in Europe. European Review May, pp. 70-88. 